\title{
Healthcare support by a Yogo teacher at a school for special needs education who experienced the Great East Japan Earthquake
}

\author{
Shiomi KANAIZUMI ${ }^{1}$, Chiharu AOYAGI ${ }^{2}$, Chieko AKUZAWA ${ }^{3}$, Hatsumi KUROIWA ${ }^{4}$, \\ Kyoko SHIMOYAMA ${ }^{5}$, Yukie MARUYAMA ${ }^{6}$, Kyoko TAMURA ${ }^{7}$ and Keiko SAKOU ${ }^{1}$ \\ ${ }^{1}$ Gunma University Graduate School of Health Sciences, Gunma, Japan \\ ${ }^{2}$ Takasaki University of Health and Welfare, Gunma, Japan \\ ${ }^{3}$ Saitama Medical University, Saitama, Japan \\ ${ }^{4}$ Kiryu University, Saitama, Japan \\ ${ }^{5}$ Teikyo Heisei University, Tokyo, Japan \\ ${ }^{6} J o e t s u$ Municipal Takashi Elementary School, Niigata, Japan \\ ${ }^{7}$ Shibata Municipal Kajikawa Junior High School, Niigata, Japan
}

\begin{abstract}
Aim: This study aimed to clarify the nature of health support activities carried out for schoolchildren by a Yogo teacher at a school for special needs education who experienced the Great East Japan Earthquake.

Methods: A qualitative case study was carried out in June 2014 and involved a Yogo teacher working at a school for special needs education in Fukushima Prefecture that was damaged by the Great East Japan Earthquake in 2011. The School Principal and Yogo teacher at the institution in question were notified of the nature of the research, and consent to participate was obtained with the return of consent forms. A semistructured interview was conducted using an interview guide developed by the author. A verbal transcript of the interview was created and qualitatively analyzed using a narrative approach.

Results: The experience of the Yogo teacher was examined in three chronological stages: (a) at the time of the earthquake; (b) during the move to an emergency shelter; and (c) after the school was reopened at a branch location. At the time of the earthquake, despite efforts to avoid inciting panic among schoolchildren, many students experienced considerable anxiety. In their lives at the shelter, it became clear that medical care for children with disabilities was not carried out on a priority basis.

Conclusions: The Yogo teacher was evacuated along with the children and was aware of the particular challenge of empathizing with the children's feelings of anxiety. The findings suggest the need for long-term health support in relation to mental health care for affected schoolchildren.
\end{abstract}

Key words: mental health, natural disaster, schools for special needs education, school health services, Yogo teachers

\section{INTRODUCTION}

The Great East Japan Earthquake that occurred on March

Correspondence: Shiomi Kanaizumi, Gunma University Graduate School of Health Sciences, 3-39-22 Showa-machi, Maebashi, Gunma 371-8514, Japan. Email: kanaizumi@gunma-u.ac.jp Received 28 September 2015; accepted 9 December 2016.
11, 2011, was a large-scale seismic disaster consisting of an earthquake off the Pacific coast of Japan's Tōhoku region (with an epicenter in the Sanriku area) which occurred at 14:46h, and included a subsequent large tsunami and aftershocks triggered by the initial earthquake. The 9.0 magnitude of the quake was the greatest ever observed in Japan, and the large tsunami generated, which exceeded $10 \mathrm{~m}$ in height in some locations and 
achieved a maximum run-up height of $40.1 \mathrm{~m}$, inflicted catastrophic damage to the Pacific coasts of the Tōhoku and Kanto regions, resulting in a large-scale disaster never seen or experienced in Japanese history (Japan Weather Association, 2011; National Police Agency, 2014).

In 2010, on the basis of past major disaster experience, Japan's Ministry of Education, Culture, Sports, Science and Technology (MEXT) developed a manual entitled Emotional Care for Children: Focus on Times of Disaster and Emergency (Ministry of Education, Culture, Sports, Science and Technology: MEXT, 2010), providing case studies aimed at deepening educators' understanding of how to provide emotional care for children in the event of a disaster or emergency, in connection with other topics such as coping methods and the promotion of health monitoring in times of crisis. The manual highlights the importance of implementing ongoing health support for affected children to ensure the early detection and support of physical and emotional health problems through such strategies as various surveys concerning emotional care, the sharing of information among faculty members, collaboration with physicians, and having an accurate grasp of contingent circumstances. In addition, the manual advices the need to prepare appropriate health support for children with disabilities by maintaining a close familiarity with their specific disabilities from the perspective of daily experience (MEXT, 2010).

Reviewing the existing literature on the psychological effect of disasters on children, Uemoto, Shioyama, and Koide (2000) have examined how the psychological impact of the Great Hanshin-Awaji Earthquake of 1995 on elementary and junior high school students was greater in terms of the degree of physical damage and emotional impact suffered. Moreover, Endo, Shioiri, and Toyabe (2007), in connection with the 2007 Chūetsu Offshore Earthquake, have identified vulnerability to trauma (and other symptoms of post-traumatic stress disorder) among the children of parents with mental instability.

As the psychological impact on children in disaster contexts has become clearer, so too has the nature of health support activities carried out by Yogo teachers who work at the schools that these children attend. A Yogo teacher is a specially licensed educator who supports children's growth and development through health education and health services on the basis of principles of health promotion in all areas of educational activities in school (Japanese Association of Yogo Teacher Education, 2012). Akisaka, Nakamura, and Satake (2002) suggest that the ongoing provision of health management and health education by Yogo teachers is important for children who continue to experience "a fear of the invisible". In a 2013 study conducted among Yogo teachers who carried out health support activities in emergency shelters at the time of the Great East Japan Earthquake, Ishihara and Kazama (2013) argue that health support activities can provide children with a sense of security, as well as provide Yogo teachers with the value of collaboration with other professions for that purpose. In addition, Takahashi, Otani, and Horikago (2013) have suggested that it is precisely because of the relationship between Yogo teachers and students, who have shared time together in the same place as a result of their experience of the Great East Japan Earthquake, that Yogo teachers are able to share the children's grief and discomfort and empathize with the children's desire to talk.

Children with special needs seem to be affected more severely by disasters. Uchida (who was employed as a Yogo teacher in a school for special needs education at the time of the Great East Japan Earthquake) has indicated the need for consideration toward schoolchildren who need medication, as well as for emergency shelters specialized for children with developmental disorders and their families (Uchida, 2013). Additionally, Torii and Yoshida (2013) has noted that, for children with developmental disorders who experienced the Great East Japan Earthquake, the terror brought on by the earthquake and the changes to their subsequent lives represent a huge source of stress, even in cases where their houses or families survived. Schools for special needs education are schools established "for individuals with visual, aural, intellectual, or physical impairments, or who otherwise possess a level of medical disability (including individuals with physical weakness) that, in addition to providing education that commensurates with the level of a kindergarten, elementary school, junior high school, or high school, are also intended to impart the knowledge and skills necessary to overcome any obstacles to learning or daily life resulting from these impairments, and so achieve independence" (School Education Act, 2009). From this, it would seem that despite existing studies of the health support activities carried out by Yogo teachers for schoolchildren who attend regular schools, there has been little research in connection with schools for special needs education, where the state of health support activities remains unclear.

To this end, this paper introduces the account of a Yogo teacher employed at a school for special needs education who personally experienced the Great East Japan Earthquake in the company of the school's students. By 
eliciting the perception of this teacher at the time of the disaster and again after the reopening of the school, as well as the nature of health support activities carried out for the students, the study conducts an empirical investigation into the health support activities provided.

The purpose of this study is to clarify the nature of health support activities for schoolchildren carried out by a Yogo teacher employed at a school for special needs education at the time of the Great East Japan Earthquake.

\section{METHODS}

\section{Research design}

This study is a qualitative and descriptive case study that uses a narrative approach. The narrative approach results from episodes given significance by virtue of their narration as a linked chain of events that are framed so as to be understood as experiences. The strength of a narrative approach is that it facilitates a transparently processual comprehension of interviewees' subjective experiences by clarifying the ways in which meaning is assigned (Kishimoto \& Saito, 2006; Saito \& Kishimoto, 2003). In this approach, assignment of meanings by the individual is clarified, and the process, in the sense of the interviewee, is understood by linking the narration of his/ her experience, in other words, empirical facts. How and what specifically is narrated are important as well. This studyused a narrative-based case study method to describe such a process in close detail, with a view to the possibility of bringing added richness and depth to the practise of health support activities among Yogo teachers.

\section{Description of the participant}

The participant was a Yogo teacher employed at a school for special needs education located in a prefecture affected by the Great East Japan Earthquake. The school was located in a city at high risk of pollution due to the nuclear power plant accident caused by the Great East Japan Earthquake, and where an all-residents evacuation directive was issued by the government. At the time, the school for special needs education in question had a total enrolment of approximately 100 students from the elementary to high school level, most of whom were with intellectual disabilities, and a staff of approximately 80 teachers. Many of the students had epilepsy or other conditions and were regularly taking medication. Several students were dependent on daily use of medical devices, such as tube suctions. The school had a student dormitory and those who lived at the dormitory were bused to and from school.

\section{Data collection}

A letter of request and a consent form were sent to the school for special needs education in question, addressed to the School Principal and Yogo teacher. Return of the consent form was regarded as consent to participate in the study. A semi-structured interview was conducted in June 2014 using an interview guide developed by the author. The interview guide was developed with reference to literature on healthcare management provided by Yogo teachers and comprised the following three parts: (a) physical and mental states of the students at the time of and after the earthquake; (b) healthcare support actions that the Yogo teacher carried out for the students; and (c) outcomes and future tasks from the interviewee's view (Aoyagi et al., 2014; Sakou et al., 2013).

During a visit to special needs school, the Yogo teacher in question was interviewed on the subject of health support activities for children at the time of the Great East Japan Earthquake. With the consent of the interviewee, the content of this interview was recorded using a digital audio recorder, and a verbatim transcript of the interview was produced. The interview was conducted in Japanese.

\section{Data analysis}

Data was analyzed using a narrative approach (Kishimoto \& Saito, 2006; Saitō \& Kishimoto, 2003). Once the contents of the recorded interview had been transcribed, a narrative was constructed from the portion of the content that was determined to be the Yogo teacher's experience, and a story divided into three distinct periods from the interviewee's point-of-view was written. Then, based on the process of the experiences surrounding the health support activities that the Yogo teacher carried out for the schoolchildren, the significance of the events (i.e. interpretation) was examined. The analysis was discussed among multiple researchers in school health nursing with experience working as Yogo teachers. Data were translated into English at the end of the analysis process.

\section{Ethical considerations}

This study was conducted with permission from the Board of Education and the School Principal with jurisdiction over the school for special needs education where the interviewee was employed. In addition, the research methods for the study were described to the interviewee both orally and in a written format, with a full explanation of the fact that participation was completely voluntary and with regards to the protection of privacy and other personal information. Written consent to participate in the study was then obtained. The content of the interview recording and transcript data 
was discarded upon completion of the study without being used for any purpose other than research. The study was approved by Epidemiologic Research Ethics Committee of the primary author's university (Approval No. 25-6).

\section{RESULTS AND DISCUSSION}

\section{Description of the interviewee}

The Yogo teacher interviewed for this study was a woman in her 40 s who had spent 8 years of her 20 -year career working at schools for special needs education. The interview lasted $67 \mathrm{~min}$. At the time of the disaster, she was employed at a school for special needs education in Fukushima Prefecture, and was evacuated in accordance with directives issued by the prefecture.

\section{Experience of the Yogo teacher and its signifi- cance}

The experience of the Yogo teacher in question was summarized into a storyline scenario (narrative description) through division into a series of three separate chronological periods. Quotes from the interviewee's own narrative are rendered in italics. Table 1 presents an overview of her experience after the disaster, divided into three separate periods.

Immediately after the earthquake (March 11-18, 2011). On March 11, 2011, the Yogo teacher was at her school at the time of the earthquake; she took shelter along with the schoolchildren under her care. Because the children in the school's elementary and junior high school departments had already left for home, the teachers for those grades were in the teacher's office, which they immediately exited to take shelter outside. Teachers in the high school department, in the midst of their cleaning period, waited for the tremors to subside before exiting the building together with the high school students to take shelter in the schoolyard. The students waited patiently with the teachers without becoming overly agitated. Although the teachers attempted to get in touch with parents to confirm the safety of the schoolchildren who already had left school, contact proved difficult due to inaccessibility of communication lines and the scattered locations of the shelters, and it was not until March 17, a full 6 days after the time of the earthquake, that teachers were finally able to confirm everyone's safety.

I think that there might have been some [students] who didn't understand at the time what was happening, and I think a tremor that big was really unsettling, but since their homeroom teachers were with them, they were okay just for that moment. It was the hardship that came later, after they were evacuated, that was really tough.

The Yogo teacher went on to recall that although the students did not appear to be outwardly agitated, many of them were not able to speak or verbally express

Table 1 Overview of interviewee details and summary of experience, and key words

\begin{tabular}{|c|c|c|c|c|c|c|}
\hline School type & $\begin{array}{c}\text { Age } \\
\text { (years) }\end{array}$ & $\begin{array}{c}\text { No. years } \\
\text { as a } \\
\text { teacher }\end{array}$ & $\begin{array}{c}\text { No. } \\
\text { years in } \\
\text { service }\end{array}$ & $\begin{array}{l}\text { Summary of } \\
\text { experience }\end{array}$ & Overview & Key words \\
\hline \multirow[t]{3}{*}{$\begin{array}{l}\text { School for } \\
\text { special needs } \\
\text { education } \\
\text { (tokubetsu } \\
\text { shien gakkō) }\end{array}$} & \multirow[t]{3}{*}{$40 \mathrm{~s}$} & \multirow[t]{3}{*}{20} & \multirow[t]{3}{*}{8} & $\begin{array}{l}\text { Immediately } \\
\text { after the } \\
\text { earthquake } \\
\text { (March 11-18, } \\
\text { 2011) }\end{array}$ & $\begin{array}{l}\text { The earthquake struck as school was being dismissed Teachers } \\
\text { exited the building with the schoolchildren and waited for } \\
\text { the earth to stop shaking, and then evacuated everyone back } \\
\text { into the school building at the Principal's instruction. } \\
\text { Children living in the dormitory had already left school by } \\
\text { microbus. Teachers walked to the station to meet children on } \\
\text { their way back home. } \\
\text { It was March } 17 \text { before the teachers were able to contact all } \\
\text { the parents and confirm everyone's safety. }\end{array}$ & $\begin{array}{l}\text { Anxiety, } \\
\text { panic }\end{array}$ \\
\hline & & & & $\begin{array}{l}\text { At the } \\
\text { emergency } \\
\text { shelter } \\
\text { (March 19- } \\
\text { April 17, 2011) }\end{array}$ & $\begin{array}{l}\text { Emergency shelters were established in students' various home } \\
\text { communities. } \\
\text { None of the schools for special needs education were designated } \\
\text { as emergency shelters. } \\
\text { Teachers toured emergency shelters to ascertain the safety of } \\
\text { students whose whereabouts had not been confirmed yet. }\end{array}$ & $\begin{array}{l}\text { Medical } \\
\text { care }\end{array}$ \\
\hline & & & & $\begin{array}{l}\text { When the } \\
\text { school reopened } \\
\text { (April 18, 2011 } \\
\text { - June 2014) }\end{array}$ & $\begin{array}{l}\text { Special needs school classrooms were opened at eight schools } \\
\text { for the disabled across Fukushima Prefecture, one of which } \\
\text { was located in the Aizu region. } \\
\text { Some students were also transferred to schools in Akita and } \\
\text { Okinawa Prefectures. }\end{array}$ & $\begin{array}{l}\text { Emotional } \\
\text { care }\end{array}$ \\
\hline
\end{tabular}


themselves, which meant that, in fact, even if they had been experiencing anxiety or fear, they might not have been able to communicate this in a clear fashion. That said, she judged that any such anxiety or panic would likely have been mitigated by the fact that the teachers had remained with their students.

Torii et al. (2013) and Uchida et al. (2013) reported how quickly children at schools for special needs education were emotionally settled by huddling together with their teachers, who firmly embraced the crying children when they became frightened with each aftershock. They also note that, while at school, teachers are the adults with whom students are most familiar, and that during the earthquake children gained a sense of security from familiar adults like teachers and parents, whose role it was to protect them.

In this study too, it was found that schoolchildren managed to avoid anxiety or panic in the immediate aftermath of the earthquake because their teachers remained constantly by their side, not leaving them even temporarily. It became clear that there are children at schools for special needs education who cannot talk or who are unable to express themselves verbally, and that it is important for those with the ability to reassure, such as teaching staff (including Yogo teachers), to remain constantly at their side and to be present to elicit and empathize with feelings of disquiet. It was suggested that the homeroom teachers, whom students normally spend the majority of their lives at school with, played an important role in providing children with a sense of security in disaster situations as well.

At the emergency community shelters (March 19April 17, 2011). Each child was evacuated to the emergency shelters established in their home communities. Because children enrolled in schools for special needs education have a variety of disorders, the Yogo teacher was fully occupied with accommodating these difficulties. She recalled her experience at the time as follows:

Since they had to leave their own homes, children with autism spent the night outside, and their mothers also spent the whole time outside with their children, unable to enter the large gymnasium. Also, since the emergency shelters and temporary housing were unlike their own homes, children ended up being admonished by those around them to keep quiet, even if they had autism or Down's syndrome, and this was difficult for the parents.

Teachers had a difficult time at the gymnasium at the evacuation location, since children with disabilities were reproached for being noisy and, in some cases, for losing control of their bladders and wetting themselves, in response to the change in environment. While it would have helped somewhat for us to have had a dedicated space, at the time there was not enough space, and in the end, it was those who were weakest-the children, elderly, and babies - who unfortunately ended up getting the worst of it.

Challenged children, especially those with autism, are vulnerable to unfamiliar environments. From her experience of the children's hardship at not having a place of secure refuge at the shelter, the Yogo teacher felt that the students may have been able to spend time at the shelter more comfortably had there been a dedicated space provided for children with disabilities.

Furthermore, it became clear that adult-focused medical care for local residents took priority in these emergency shelters.

Physicians and public health nurses toured the emergency shelters about once a week. However, their care was oriented to general adult needs, and children from the schools for special needs education were outside of their purview.

If we had had prescription records, we could have had a better grasp of what medications the children were taking, and it might have been possible to get the prescriptions filled at a standard pharmacy.

Although there were some children attending schools for special needs education who were taking medicine, the medications in question were not kept at the school, and information about which child was on which medication was held by only the infirmary of the school; neither the Yogo teacher or homeroom teachers kept that information with them. Nor were the children at the school for special needs education all evacuated to the same shelters; they had been taken by their parents and evacuated to separate shelters. This meant that the medical care available at each shelter differed, and that the Yogo teachers themselves were not necessarily housed in the same shelter as their students. In light of these experiences, the Yogo teacher felt that it might have been possible to fill the medical prescriptions at a pharmacy, even during the crisis, had the children each had individual prescription records with them at the shelter.

Uchida (2013) pointed out the need for emergency shelters for children with developmental disorders and their families, as well as the need to enhance cooperation with municipal disaster prevention offices and make preparations such as by drafting broad rules for operating shelters and supplying them with substantial stockpiles. In this study, too, it was found that the medical care in emergency shelters tended to give priority to typical 
adults, whereas there were many difficulties in the shelters for children, who, as a result of their disability, would sometimes spend nights outside, being unable to enter emergency shelters, or else be reproached by those around them for being too loud. There is an urgent need to establish systems for providing medical care, such as dedicated emergency shelters and spaces for children with disabilities and their families, so that they may be able to enjoy security when living in the shelter. In particular, because the administration of oral medication has a direct link to the lives of schoolchildren attending schools for special needs education, strategies for the management of medication will also need to be examined at the earliest possible opportunity.

When the school reopened (April 18, 2011 to June 11, 2014). Because schoolchildren were regularly forced to change their evacuation location and, moreover, because teachers had to carpool to tour the various sites due to gasoline shortages, there were delays in confirming the safety of all of the children. On April 18, 2011, the school was reopened at eight branch classrooms across the prefecture.

A branch classroom was established for us here at (the evacuation point) in Aizu, and it was arranged that a number of students would begin to attend school here. Teachers were also evacuated here in consultation with their intentions for the school. Due in part to my own family circumstances, I confirmed that I would be able to relocate to this school, and as a result I was stationed here as a Yogo teacher over a year ago now.

It was revealed that the emotional care for schoolchildren was carried out not by Yogo teachers directly, but rather primarily by the homeroom teachers who were the most familiar to the schoolchildren, whereas Yogo teachers would actively listen to the homeroom teachers and provide support for them.

While I think that the emotional care of the children was the main thing, and while it would have been better if the number of teachers stationed at each of the branch classrooms commensurate to with the number of students, it seemed to me that students and teachers alike were just thrown together without any plan-they didn't seem to understand even the numbers involved. There were some students who ended up in Akita and Okinawa, and in fact, out of the 100 children, I think there were only about half who were left to attend the branch classrooms. Since carrying out educational activities at each branch classroom in line with the curriculum of each of the schools where they were placed followed a single stream, I think that what we were most worried about first of all was familiarizing the children with the new environment at the branches where their teachers had been stationed. Although, obviously, there were some children who would respond to words like "tsunami" and "earthquake" by creating art that was completely black, it was our impression as teachers that the children also grew more settled by working in the branch classrooms to get back to the regular life rhythms we had had previously.

When Yogo teachers began conducting regular health check-ups in April, they had more opportunities to interact with the schoolchildren directly in terms of preparation, inquiries, helping during the physician's check-ups and follow-up consultations.

I guess what I did in the Aizu branch classroom was to try to stay involved so that students attending the school would be able to have a normal school experience. Beginning with the health check-ups in April, I tried to help them really be able to get back to their usual school lives.

As the Yogo teacher also experienced the earthquake, she was able to understand the children's emotions, even when they were not able to verbally express themselves well. Even so, she reflected that had she been slightly more skilled in techniques for eliciting the children's thoughts and feelings of unease, she might have been able to provide the students with greater emotional relief. She felt that it was important for students to be provided with support that would enable them to feel a sense of security, even if only to a small degree.

Since I'd also gone through the same experience myself and felt some of the same anxieties, I could make the children feel that we had that in common, helping them to interact with me verbally. I guess since there are a lot of teachers who know what those children like and who were there by their side, I think it's important to provide them with the various forms of support that will help them be able to feel a sense of security, even if only a little. Because every one of these children has his or her own preferences and individuality, I believe that knowing these things is crucially important. And, while I guess that their parents, who usually spend the most time together with their children obviously provide the greatest security, teachers are also people who can provide security, since they are together with them every day from morning until around two in the afternoon. So, while we were separated into the branch classrooms, I still thought that the connection was important, since I knew that the kids would still be overjoyed when we ran into each other again.

Takahashi et al. (2013) describe as a "symbol of security" the presence of teachers who, having shared the experience of the disaster together in time and place, are 
therefore able to share children's grief and discomfort and empathize with what their students wish to express. In this study, even though the Yogo teacher had relatively few opportunities to interact directly with the schoolchildren, the fact that she herself also experienced the disaster suggests that she may be presumed to have been able to understand the children's feelings. The resulting pattern was one in which the Yogo teacher would, among other things, listen to the stories of schoolchildren who came to the school infirmary, while emotional care was being provided primarily by homeroom teachers, who generally had spent the longest time together with the schoolchildren and therefore knew them best.

From the fact that the MEXT handbook (MEXT, 2010) stipulates the need for long-term support for children affected by deep emotional wounds, it is clearly important for schools, households, and the local community to come together in the provision of support. In future, emotional care will become even more of an essential component in terms of support over the long term. It will be necessary for such long-term support to be carried out not only by teaching staff in schools, but also in collaboration with other disciplines, including school counselors and clinical psychologists.

\section{CONCLUSION}

\section{Experience of Yogo teachers at schools for special needs education}

By using a narrative approach method to tell the story of a Yogo teacher who experienced the Great East Japan Earthquake together with schoolchildren and then carried out health support activities, from her own perspective, this paper examined the significance of the experience by dividing it into three separate chronological periods. These three periods were summarized as processes occurring "immediately after the earthquake", "at the emergency shelter", and "after the school reopened".

The Yogo teacher experienced the disaster at the school where she was employed and was evacuated along with the school children. Because these were students who attended a school for special needs education, she was aware of the particular challenge of how to empathize with the children's feelings of anxiety. At the time of the disaster, homeroom teachers played a central role in the emotional care for schoolchildren, while listening to them tell their stories in order to alleviate their feelings of anxiety or panic. In addition, Yogo teachers, keenly aware of the need to provide emergency shelters for children with disabilities, listened to the stories of schoolchildren who, as a result of their disabilities, often were insistent on sameness or inflexible adherence to routines (e.g. extreme distress at small changes, difficulties with transitions or rigid thinking patterns) (American Psychiatric Association, 2013) and spent the night outdoors, unable to enter the emergency shelters.

Subsequently, in April of 2011, the school was reopened as multiple branch classrooms of a school for special needs education at eight locations throughout the prefecture, and when the schoolchildren were moved to a temporary school for special needs education that opened in Aizu in April of 2013, the Yogo teacher transferred there voluntarily. At this time, the Yogo teacher's entire family moved, to begin life anew at the evacuation point. Even when the school reopened, however, she spent her days putting her experience of the Great East Japan Earthquake to use, reflecting on issues such as the problem of emotional care, the preparation of shelters in the event of the occurrence of another major earthquake, emergency supplies, and medication that should be stockpiled in the school infirmary. In particular, with regard to emotional care, even though she could understand the students' feelings as she herself also experienced the disaster, she also recalled that if she had better known how to elicit the children's feelings, she might have been able to provide a slightly different type of support.

\section{RECOMMENDATIONS AND FUTURE CHALLENGES}

This paper used a narrative approach to undertake an empirical examination of the experience of a Yogo teacher at the time of the Great East Japan Earthquake, and its meaning. Anxieties and panic among the children, medical care, and emotional care were revealed to be of concern. Recommendations in Yogo teachers' school health practice for supporting children with special needs in an event of disaster are as follows: (a) to be constantly present at the side of schoolchildren, while listening to them tell their stories in order to alleviate their feelings of anxiety and provide them with a sense of security; (b) to provide a dedicated space for children with disabilities and who require accommodation for their special needs at emergency shelters; (c) to gather and safely transport the healthcare documentation and medication records of schoolchildren from the school in case of evacuation; and (d) to facilitate collaboration with healthcare professionals and psychologists in order to provide early intervention regarding the emotional care for the children.

This study is significant in that, now, 3.5 years after the Great East Japan Earthquake, it has brought some clarity 
to the health support activities carried out by Yogo teachers for students at schools for special needs education. However, this interview represents only a single case study; therefore, limits to its generalizability or universalizability exist. There remains a need for the accumulation of additional research data in future.

\section{ACKNOWLEDGMENT}

In carrying out this study, we would like to express heartfelt thanks to the yogo teacher who, despite having undergone experiences both officially and personally that would be impossible to describe, still warmly agreed to participate in the study if her story could be of even a little use to others. We sincerely pray for the rapid recovery of the areas affected by the disaster.

We would also like to acknowledge the contributions of our colleagues Nanako Matsuzaki, Hitomi Kubo, and Aya Imai on preparation of this paper.

This study was part of a body of research carried out with the assistance of a 2014-2018 KAKENHI Grant-in-Aid for Scientific Research (C) (Project No. 15K11693).

\section{DISCLOSURE}

The authors declare no conflict of interest.

\section{AUTHORS' CONTRIBUTIONS}

KS contributed to the conception and design of this study; KS, CA, and H.K. conducted the interview and drafted the manuscript; $\mathrm{CA}, \mathrm{KS}$ in pediatric nursing perspective and $\mathrm{YM}, \mathrm{KT}$ in school health perspective performed the qualitative data analysis; SK critically reviewed the manuscript and supervised the whole study process.

\section{REFERENCES}

Akisaka, M., Nakamura, T., \& Satake, T. (2002). Risk management and role of schools of the Tokai-village radiation accident in 1999 - (1) Safety education and risk management before and during the radiation accident from the standpoint of school nurse teachers. Japanese Journal of School Health, 44(2), 106-116. (in Japanese)

American Psychiatric Association (Ed.). (2013). Autism Spectrum Disorder. In Diagnostic and statistical manual of mental disorders (5th ed., pp50-59) (DSM-5). Washington, DC: American Psychiatric Publishing.

Aoyagi, C., Akuzawa, C., Maruyama, Y., Tamura, K., Shikama, K., \& Sakou, K. (2014). Mental and physical health condition of schoolchildren and health support services provided by Yogo teachers after the Great East Japan Earthquake (2nd Reports). Japanese Journal of School Health, 56, 228-237. (in Japanese)

Endo, T., Shioiri, T., \& Toyabe, S. (2007). Effect of the 2004 Niigata-Chuetsu earthquake on children's behavior. Clinical Psychiatry, 49(8), 837-843. (in Japanese)

Ishihara, K., \& Kazama, Y. (2013). Activities of Yogo teachers at refuge centers following the Great East Japan Earthquake: Based on findings from Ibaraki Gakkō hoken kenkyū. Japanese Journal of School Health, 55(1), 24-34. (in Japanese)

Japanese Association of Yogo Teacher Education. (2012). Explanation of technical terms for Yogo teachers (2nd ed.). (in Japanese)

Japan Weather Association. (2011). Overview of the TohokuPacific Ocean earthquake and tsunami [Cited 1 June 2014.] Available from http://www.jwa.or.jp/news/docs/ tsunamigaiyou3.pdf (in Japanese)

Kishimoto, N. \& Saito, S. (2006). Revaluation of the case study as a human science-oriented research method: From the perspective of narrative-based medicine. Japanese Journal of Psychosomatic Medicine, 46(9), 789-797. (in Japanese)

Ministry of Education, Culture, Sports, Science and Technology. (2010). Emotional care for children: Focus on times of disaster and emergency. Tokyo: MEXT. (in Japanese)

National Police Agency. (2014). Damage conditions and police measures [Cited 1 June 2014.] Available from http://www. npa.go.jp/archive/keibi/biki/higaijokyo.pdf (in Japanese)

Saitō, S., \& Kishimoto, N. (2003). Methodology of NBM. In The practice of narrative-based medicine Tokyo: Kongō Shuppan (pp. 62-92). (in Japanese)

Sakou, K., Aoyagi, C., Akuzawa, C., Nakamura, C., Toshima, Y., \& Shikama, K., (2013). Mental and physical health condition of schoolchildren and health support services provided by Yogo teachers after the Great East Japan Earthquake. Japanese Journal of School Health, 55, 446-457. (in Japanese)

Suzuki, I. (Ed.) (2009). Article by article School Education Act (7th ed.). Tokyo: Gakuyo Shobo. (in Japanese)

Takahashi, M., Otani, N., \& Horikago, C. (2013). What school nurses learned from the Great East Japan Earthquake: Through high school nurses' supporting activities in tsunami-stricken areas. Journal of Japanese Association of Health Consultation Activity, 9(2),138-147. (in Japanese)

Torii, M., \& Yoshida, K. (2013). How did children with developmental disorders experience the Great East Japan Earthquake: The earthquake disaster experience and steps toward recovery in children. Japanese Journal of Child and Adolescent Psychiatry, 54(5), 71-83. (in Japanese)

Uchida, K. (2013). Daily life and support among special needs students who experienced the Great East Japan Earthquake. School Health Counseling Research, 10(1), 74-75. (in Japanese)

Uemoto, M., Shioyama, A., \& Koide, K. (2000). The mental health of school children after the Great Hanshin-Awaji Earthquake: I. Epidemiological study and risk factors for mental distress. Psychiatria et Neurologia Japonica, 102(5), 459-480. (in Japanese) 